\title{
UNIVERSITYOF
}

FORWARD

THINKING

WESTMINSTER用

WestminsterResearch

http://www.westminster.ac.uk/westminsterresearch

\section{Conversations about the elections on Twitter: Towards a structural understanding of Twitter's relation with the political and the media field \\ D'heer, E. and Verdegem, P.}

This is a copy of the accepted author manuscript of the following article: D'heer, E. and Verdegem, P. (2014) Conversations about the elections on Twitter: Towards a structural understanding of Twitter's relation with the political and the media field. European Journal of Communication, 29 (6), pp. 720-734, doi:10.1177/0267323114544866. The final definitive version is available from the publisher Sage at:

https://dx.doi.org/10.1177/0267323114544866

(C) The Author(s) 2014

The WestminsterResearch online digital archive at the University of Westminster aims to make the research output of the University available to a wider audience. Copyright and Moral Rights remain with the authors and/or copyright owners.

Whilst further distribution of specific materials from within this archive is forbidden, you may freely distribute the URL of WestminsterResearch: ((http://westminsterresearch.wmin.ac.uk/)).

In case of abuse or copyright appearing without permission e-mail repository@westminster.ac.uk 


\title{
Conversations about the elections on Twitter: Towards a structural understanding of Twitter's relation with the political and the media field
}

\begin{abstract}
This study uses network analysis to examine Twitter's level of autonomy from external influences, being the political and the media field. The conceptual framework builds upon Bourdieu's field theory, appropriated on social media as mediated social spaces. The study investigates conversation patterns on Twitter between political, media and citizen agents during election times in Belgium. Through the comparison of conversational practices with the positions users hold as political, media or citizen agents, we understand how the former is related to the latter. The analysis of conversation patterns (based on replies and mentions) shows a decentralized and loosely knit network, in which primarily citizen agents are present. Nonetheless, the prominence of citizens in the debate, mentions or replies to political and media agents are significantly higher, placing them more centrally in the network. In addition, politicians and media actors are closely connected within the network, and reciprocal communication of these established agents is significantly lower compared to citizen agents. We understand different aspects of autonomy related to the presence, positions and practices of the agents on Twitter and their relative positions as politicians, media or citizens. To conclude, we discuss the promises of Bourdieu's relational sociology and the limitations of our study. The approach proposed here is an attempt to integrate existing work and evolve towards a systematic understanding of the interrelations between political, media and citizen agents in a networked media environment.
\end{abstract}

\section{Keywords}

Elections, field theory, network analysis, political communication, Twitter networks

\section{Introduction}

Since the early 1990 s, research has focused on the potential of the Internet to reproduce or revert to traditional hierarchies of power or influence, thereby indicating a transforma- tion in form and repertoires for political communication (Lilleker and Vedel, 2013). Concerning social media in particular, these are associated with the inclusion of multiple citizen actors in the political debate, which is traditionally dominated by 'established authorities', like 
politicians and mainstream media. In this article, we focus on the use of Twitter during elections, characterized by intensified relations between politicians, mainstream media and citizen-voters through various media platforms (Howard, 2006). We focus on this period of heightened activity to study Twitter conversation and the relative positions of political, media and citizen agents within the debate.

Internet research on campaigning and the elections is traditionally based on content analysis, whereas the network structure of the Internet has been underused for a long time (Lilleker and Vedel, 2013). Over the last few years, the use of social media (notably Twitter) in political discussion has received considerable attention by scholars, in part related to the success of Obama's 2008 social media campaign. Hence, numerous studies focus on the activities of specific traditional political actors (politicians and parties) on the platform during election times (e.g. Bruns and Highfield, 2013; Graham et al., 2013; Vergeer et al., 2011). In addition, beyond politicians, we have studies that point to the role of journalists in the political debate (e.g. Bruns and Burgess, 2011; Larsson and Moe, 2012) and, to a minor extent, activities of citizen users are also included (e.g. Ausserhofer and Maireder, 2013). Through empirical inquiry, in which content analysis and also network analysis have their place, these studies contribute to the understanding of the role of Twitter in the public debate. There is a general consensus that virtual spheres mirror existing social structures - how established actors seem to dominate these digital arenas for political communication. Our question here is 'How can we conceptualize and empirically investigate this in a systematic manner?'

In order to engage with this question, we put forth an approach that is based on Bourdieu's field theory, which has been appropriated on the participatory web or 'web 2.0' (Song, 2010), and social network technologies in particular (Papacharissi and Easton, 2013). We introduce and adapt Bourdieu's tools for the current research question rather than a thorough elaboration upon its potential for media and communication research (see Benson and Neveu, 2005; Couldry, 2003). As we outline below in the theoretical framework, we appropriate the concepts of 'field' and 'autonomy' that Bourdieu (1988) uses to look for 'a resemblance within a difference' (p. 178), that is, relatedness between the fields. We start from the assumption that positions and conversation practices of the agents on Twitter are related to the positions and practices of the agents in other fields, whereby we particularly focus on the political and the media field. 
This article starts with a theoretical outline of the field approach to understand the role of social media in the public debate. In addition, we explain the Belgian case as well as the data and analyses we conducted. Following, we present the obtained findings, whereby we discuss conversation patterns between the agents in relation to their positions as political, media or citizen agents. The final section allows for overarching conclusions, limitations and opportunities for further research.

\section{Theoretical framework}

\section{A social media logic and the notion of autonomy}

Although we focus on Twitter, with its socio-technological particularities, social media platforms as a collective are characterized by a network logic (Svensson, 2011) and in broader sense a social media logic (Van Dijck and Poell, 2013). Without thorough elaboration, the notion of logic acknowledges the way media shape politics and, in a broader sense, society. For this study, we particularly focus on the technological affordances of these platforms to influence social relations and communication, as well as the nature and function of the relations between political, media and citizen agents.

As mentioned above, the concept of logic, applied on traditional as well as social media, aims to understand the 'dependency of society on the media and their logic' (Hjarvard, 2013: 17). In this respect, we can say that it looks inside-out (i.e. how media influence society). When we relate it to the concept of field, we use the concept of logic to look outside-in (i.e. to understand how external influences co-define the logic of these social media platforms). In this study, we focus on conversation patterns between politicians, media and citizens on Twitter. We acknowledge that these practices are both afforded by technology, but they also reflect the user's resources and dispositions.

According to Benson (2009), the promises of the field approach are in the opportunities to describe and explain variations in media logic. These variations can be found through a systematic comparison with related fields and their logics. Our approach is distinct from celebratory interpretations suggesting egalitarian, non-linear and decentralized relations between the agents based on social media characteristics (Benkler, 2006; Gillmor, 2004; Heinrich, 2011). More specifically, Castells (2009) relates communicative autonomy (i.e. capacity of the new communication systems to communicate at large) with social and 
political autonomy of the user. Hereby, he ignores the collective dimension or the relative autonomy of the individual, as rightly addressed by Fenton and Barassi (2011). In this context, it is relevant to introduce Bourdieu's notion of autonomy as related to the field concept (Bourdieu, 1984; 1990). Via this notion, we alter our scope from the autonomy of the individual (i.e. a micro perspective) to the autonomy of the field (i.e. a meso-level understanding). Compared to habitus and social capital, these concepts remained relatively undeveloped (Bourdieu, 1993), yet we find them promising in order to understand the structural characteristics of conversation patterns between political, media and citizen agents on the Twitter platform. As outlined below, the concept of autonomy provides a systematic understanding of the relation between social media platforms (and their characteristics) and the political and the media field. Although we acknowledge its use goes beyond civic and political purposes, we focus on the political debate on Twitter.

\section{Related fields and the notion of autonomy}

According to Bourdieu $(1984,1993)$, a field is an arena of social or cultural production that consists of agents (individuals, groups or institutions) that comprise positions within the field and are in a dynamic relation with one another. Of particular interest here is the notion of autonomy of the field or the way it generates and acts upon its own values or 'logic' (i.e. heteronomy) or acts alike other fields (i.e. homology). Bourdieu uses the language of 'homology' to explain the effects between the fields, which are never direct, but are referred to as 'correspondence' in structures and processes between fields. Here, we focus on the relation between Twitter (as a field), the media field (or 'journalistic field', Benson and Neveu, 2005) and the political field (i.e. institutional politics, parties and professional politicians, Bourdieu, 1991). Twitter is understood as a field in the sense that it reflects an arena of social activity which has its own modus operandi, characteristics and structured positions. We acknowledge the study of the political and the media field is historically informed and well documented in the literature. Nonetheless, following Kauppi (2003: 778), no particular unit is excluded for field analysis. Below, we formulate and elaborate on our central research question:

$R Q:$ How do conversation patterns between political, media and citizen agents on Twitter reveal Twitter's relatedness to the political and the media field? 
Answering this question allows us to understand the autonomy of Twitter from the political and the media field and its place in public debate in relation to those fields. In reference to Maton's (2005) conceptual work on the notion of autonomy, we particularly focus on positional autonomy, which reflects the relation between the positions agents occupy on Twitter and their location in other fields (i.e. political or media). The position of the agents on Twitter (or any other field) reflects the distribution of the relevant kinds of capital (or power) (Bourdieu, 1988). Bourdieu (1986) distinguishes economic capital (which is selfexplanatory), cultural capital (i.e. education, social and professional experience) and social capital (i.e. a durable network of relations). More ambiguous in nature is the notion of symbolic capital, which is said to legitimate other forms of capital and overlap extensively with social capital (Bourdieu, 1986; Swartz, 1997). In essence, it can be understood as the legitimation (Bourdieu, 1986) or the recognition agents receive from the group (Bourdieu, 1991: 72), which is, at the end, at stake in any social field.

In this study, we focus on Twitter conversation practices as well as the positions the agents hold in the conversation network. Both practices and positions are empirically related to the positions the agents hold in the political and the media field, each with their own logic of practice. Concerning these conversation networks, we formulate how the affordances of social media can influence (1) politicians' relation with citizens, as an electorate, and (2) media's relation with citizens as an audience:

1. The presence and practices of formal political agents (politicians and parties) on Twitter allows interactivity and more direct forms of participation with citizens, who then become part of the political public field (Friedland et al., 2006). Networking technologies allow immediate, two-way channels of communication, un-mediated by traditional media, which reflects more direct forms of politics or 'politics of nonrepresentation' (Fenton, 2012). In addition to the altering nature of the debate, it is also broadened by the inclusion of more voices to enter and join the discussion (Fenton, 2012).

2. The advent of social media is often related to the changing relationship between producers and consumers of content (Bruns, 2005; Jenkins, 2006). Otherwise stated, the broadcasting logic (of corporate media) meets the logic of convergence (or bottom-up participatory culture) (Sjöberg and Rydin, 2013). Concerning the Twitter platform, Rieder (2012) puts forth the notion of 'refraction'. Based on a study of 
Twitter messages, he acknowledges Twitter as a 'refraction chamber', as it alters existing traditional news and information flows (rather than being an independent space). The metaphor of refraction is used by Bourdieu (1993) as well, that is, the way the field 'refracts' external influences. Via our conversation networks, we aim to understand how relations between citizens and media organizations or journalists on Twitter are structured.

The 'field' concept allows us to understand the relation between political, media and citizen agents and the 'effects' these fields have upon one another in the public debate. It is these unintentional effects, captured through the language of 'homology' (i.e. indirect links), that are important to define power relations as the platform's affordances for communication and interaction are inclined to conceal or disguise those in power. This can be understood as the 'conversationalization' of the public discourse (Fairclough, 1994) and entails a critical understanding of the evolution of public debate, as it evolves towards the adoption of informal, conversational language and practices, but does not necessarily reflect a real shift in power.

The understanding of the relations between the fields is at the heart of our methodology, that is, network analysis. The application of network analysis for the investigation of social fields was initially criticized by Bourdieu but, through its evolution and developments, has been revisited as a method to assess fields (De Nooy, 2003). The point of the study is not to provide exhaustive empirical evidence on Twitter's interrelation with the political and the media field, but to provide a number of findings that illustrate their systematic interdependence. The Belgian case is discussed below, as it fits within but does not constitute the overarching framework. We do acknowledge the dependency and autonomy between the fields may vary across societies.

\section{Research design and rationale}

Below we document the choices we made concerning data collection and analysis. The empirical appropriation of Bourdieu's conceptual tools, mainly 'field' and 'autonomy', brings forth contingencies and challenges related to the ambiguities linked with the concepts (Couldry, 2003). We outline the Belgian case and elaborate on the choices we made concerning Twitter data collection and processing in the light of the network analysis we conducted. 
The country under investigation is the Western European country of Belgium. Based on the models of media and politics that Hallin and Mancini (2004) distinguish, Belgium represents a democratic corporatist model. Without extensive elaboration upon all its dimensions, it signifies media autonomy and journalistic professionalization, early development of the mass-circulation press and strong public service broadcasting.

Here, we focus on Flanders, the northern part of Belgium and home to the Dutch-speaking community. In the Belgian federal state, press, information, culture and audiovisual matters have been allocated to the communities. When we speak of national media, these reflect Flemish media, as there are no national media for Belgium (De Bens and Raeymaeckers, 2010).

The article represents Twitter data of the provincial, municipal and district elections of 2012 that took place on 14 October. The electoral context in Belgium is characterized by a multiparty system, whereby parties compete against one another but must work with each other to form a coalition. Important to mention here is that voting is mandatory in Belgium. Despite the distinct local and regional orientation of the elections, national mainstream media devoted a lot of attention to it (Epping et al., 2013). During election times, the importance and influence of mass media increases, for national as well as local campaigning (Van Aelst, 2008). In addition, this post- broadcasting era reflects a fragmented news environment in which citizen users, but also politicians and journalists, can embrace the interactivity and autonomy that is often associated with this networked media environment (Prior, 2006). This is true for local elections where personal information and mobilization of voters is highly valued (Van Aelst, 2008). Nonetheless, Twitter usage is higher for politicians active at the Flemish level compared to the local level. Concerning the latter, $14 \%$ of the municipal governments and about $11 \%$ of the mayors have a Twitter account compared to $60 \%$ of the members of the Flemish parliament. ${ }^{1}$ Both local and regional politicians took part in the election debate on Twitter.

\section{Data collection}

The Twitter Application Program Interface (API) allows us to capture tweets containing a certain keyword or hashtag using the open-source tool yourTwapperkeeper (yTK) (Bruns, 
2012). Following this procedure, we collected a corpus of 43,447 tweets containing the general hashtag of the local elections (\#vk2012). We acknowledge that the hashtag approach is not comprehensive but it is nonetheless commonly applied for data collection during election times (Bruns and Burgess, 2011; Bruns and Highfield, 2013; Larsson and Moe, 2012). Moreover, in Belgium, the hashtag was consistently initiated and supported by the mainstream media (e.g. through display on the TV screen), which contributed to the general adoption of the hashtag by Twitter users. However, as Larsson and Moe (2012) rightly stress, accidental contributions or more inexperienced users might be left out. In addition, these scholars acknowledge the limitation of the hashtag approach concerning the inclusion of follow-up messages; nonetheless, they point to the use of the hashtag as the user's intentional contribution to the public debate. These hashtags are clickable and searchable, which contributes to their visibility.

The 43,447 messages correspond to 11,658 users participating publicly in the election debate. Despite its substantial number, we make no attempt to generalize this specific userbase to the wider population or the electorate as such. Apart from users that represent politicians and/or political parties and media institutes, it is likely we are also dealing with 'political junkies' (Coleman, 2003) or in similar vein 'news junkies' (Prior, 2006).

The adoption of Twitter by the Dutch-speaking community in Belgium lags behind other social media platforms, such as Facebook (62\%). Twitter usage is on the rise though, with a $13 \%$ increase compared to 2011 , resulting in $27 \%$ that have an account (iMinds- iLab.o, 2012).

For the construction of our conversation networks, we extract from the corpus all messages that contain 'markers for addressivity' (Papacharissi and De Fatima Oliveira, 2012), that is, tweets including@signs in the form of replies (tweets that start with ‘@ name’) and mentions (tweets with '@name' in the text). Hence, only about 16\% of the original number of messages was retained. These percentages are comparable to other studies on social media and elections making use of the hashtag approach (Bruns and Burgess, 2011; Larsson and Moe, 2012). Replies and mentions allow the user to specifically, yet publicly, address specific other users (Honeycutt and Herring, 2009). Replies and mentions reflect conversation practices as well as positions. According to Ausserhofer and Maireder (2013), these markers indicate one's authority in the network. In this respect, we relate the struggle over symbolic capital (i.e. the legitimation on Twitter) to the number of replies and mentions 
one receives in the network. In combination with the sender's identity (as we discuss below), this allows us to understand how positions (and practices) of Twitter users are structured.

\section{Data processing and analysis}

The discussion of the Twitter network is based on a comparison between four distinct but subsequent stages in the conversation, as they show differences in traffic as well as in meaning: campaign (pre-election), Election Day and post-campaign (post-election). Concerning the election campaign, the week before the elections shows a steady increase in Twitter traffic and is defined as a separate period, resulting in four networks: (1) 1 September 2012 to 7 October 2012 (pre-election), (2) 8 October 2012 to 13 October 2012 (prior week), (3) 14 October 2012 (Election Day) and (4) 15 October 2012 to 21 October 2012 (postelection).

We use the Social Network Analysis (SNA) software UCINET (Borgatti et al., 2002) to analyse the consecutive networks, which allows a comparative and more detailed understanding of the conversation. In order to understand how positions and practices of Twitter users are related to their identity as a political, media or citizen agent, we coded the senders and receivers of the messages accordingly. We acknowledge that Twitter identity is problematic as it is self-defined and therefore does not always (or ever) fit traditional categorization schemes (Lewis et al., 2013). In addition, user identities can be absent or updated and modified invariably. The definition of users as political, media and citizen agents is based on their username and description, as publicly available, at the time the network analysis was conducted (April 2013). The actors can reflect entities (e.g. parties) and individuals (e.g. politicians). Although we acknowledge identity as a plural process, as we operate in multiple different contexts, we define political and media agents in terms of their formal, professional identity. Whereas the definition of media and political agents is salient, this is less the case for citizen users. We opted for a rather rigid approach here, excluding users that are publicly affiliated with (or represent) political/governmental organizations, media institutions and other non-governmental organizations (NGOs) or movements that are political in nature (such as unions). In addition, accounts that relate to municipalities or events are excluded as well. We acknowledge that this influences the network but, in order to understand the relationship between the three agent types, clear categories reveal the relations and networks we are most interested in. 
Using the social network analysis (SNA) terminology, the type of relation studied here is 'interaction' (i.e. talking with) (Borgatti, 2007). The strength of the relation is measured by frequency (i.e. how many times two users interact). Understanding the autonomy of Twitter lies in the statistical comparison of the characteristics of the net- work structure (i.e. positions and practices) in relation to the identity of users (i.e. politician, media and citizen). The meaning of these analyses becomes clear throughout the discussion of the results.

\section{The structural understanding of the debate}

The discussion of our findings starts with an assessment of the network, as an objective structure, reflecting the positions agents occupy in the network, as politician, media or citizen. Thereafter, the characteristics of the conversation networks are defined, to end with a comparison between both the objective and inter-subjective structures to under- stand how the former is related to the latter.

\section{The objective structure of the network}

We start with an overview of the different agents that make up the network for each of the periods under analysis. More specifically, Table 1 provides the number of agents that address and/or were addressed during the four specific periods. It is through their positions within the field, as political, media or citizen-user, that agents are objectively related, in a sense that these relations appear even when there is no interaction.

As Table 1 shows, the structure of the network changes in an objective sense (i.e. the constellation of agents in terms of their objective position). Change is primarily related to the drop in politicians' presence in the debate (from $35 \%$ and $30 \%$ to $11 \%$ and $17 \%$, see Table 1). It seems that politicians mobilize or inform (or are mobilized or informed) more before Election Day, or when the stakes are higher, than after Election Day. As shown in Table 1, aside from politicians, the relative numbers remain largely stable. The high number of citizen agents in the debate is similar to research on interaction patterns in the Austrian political Twittersphere, where about half of the users were citizens with- out professional political affiliation (Ausserhofer and Maireder, 2013). In this respect, the variety of agents shows that presence in the conversation network is fairly unrelated to one's position in the media or the political field. 
In addition to presence, we want to relate the positions the agents hold in the conversation network with the positions they hold as a political, media or citizen agent. Before doing that, we describe the conversation networks (i.e. the inter-subjective relations between the agents) as such, using a selection of SNA measures. First, we calculated the density of the network (or the number of connections between users divided by the number of total possible connections), which shows how tightly knit the network is. Second, network centralization indicates the network's tendency towards centrality or the concentration of interactions around a few particular agents. For both measures, no significant differences were found between the four networks reflecting the four periods under analysis (i.e. the election campaign, the prior week, Election Day and the week after the elections). Hence, for reasons of clarity, we dis- cuss these results as a collective in the paragraph below, but the specific values can be found in the endnote below. ${ }^{2}$

The density of the conversation networks is very low (i.e. below 1\%). This means that we found very little interaction among the different agents in our networks, given the total amount of agents in the networks. Most of them are only connected to one other agent in the network. Although the hashtag is clickable and searchable, which allows users to interact with users beyond their timeline, this potential is not necessarily put into practice. Concerning network centralization, the measures are rather low as well (i.e. around 5\%), suggesting variance in the distribution of centrality in the networks. This means that a lot of different users address a lot of different other users, rather than one or a few central users surrounded by peripheral ones.

Finally, we look at the strength of the interactions, that is, how frequently users inter- act with others. For the networks in general, the average number of messages sent/ received per agent is no greater than two. This means that most relations between users in the network reflect one or two mentions or replies. We do note that the distribution of the messages is skewed to the right, meaning that most agents send (or receive) only one or two messages and a very few agents send (or receive) a lot of messages. This is the power law distribution (or long tail), which applies to user activity on social media in general and creates inevitable inequality in engagement (Shirky, 2008). 
The combination of the measures shows dispersed networks with great variation in the centrality of the positions the agents occupy in the networks. Below, we account for this variation, as we distinguish between political, media and citizen agents.

\section{How inter-subjective structures relate to objective structures}

Below, we present three measures (and three tables) that refer to the conversation structure of the networks and how this relates to the objective positions of agents, that is, politician, media or citizen.

First, for each of the four periods, we look for differences between political, media and citizen agents concerning the number of replies or mentions they received and sent. For outdegree (messages sent), no differences between the different agent types were found. For indegree (messages received), however, we found significant differences between political, media and citizen actors. In Table 2, we provide an overview of aver- age number of replies and mentions each of the agent types receive and the significant differences between them (based on the $F$ statistic included in the table). Hence, what we find is that the central positions in the conversation network are related to the objective positions these agents occupy in the network (as political, media or citizen agent). The variation in centrality in the conversation networks (as discussed above) cannot be mis- taken for an egalitarian structure. Taking part in the discussion is one thing but taking position is another. Whereas the conversation networks are dominated by citizens in terms of presence, the central positions are related to political and media agents.

Taking a closer look at the variation between the different periods, we see that political agents receive more replies and mentions on and after Election Day. Future research, focusing on the content of the messages, could indicate whether communication on and after the elections reflects the confirmation and dissemination of the election results and whether communication prior to the elections serves to make more informed voting decisions.

Second, given our interest in the relations between political, media and citizen agents, we conducted an External/Internal ratio analysis, or E-I index, to define to what extent the overall networks are characterized by out-group as opposed to in-group relations (Krackhardt and Stern, 1988). Here, we aim to understand to what extent the three agent types communicate with one another or whether for example politicians mainly communicate with 
other politicians. Only on Election Day and the week after the elections (Periods 3 and 4) do the measures indicate a different network structure from what can be expected, taking into account the group sizes and network density (Hanneman and Riddle, 2011) (see Table 3). Hence, we focus on rows 3 and 4 in the table.

The significant measures for Election Day and the week after reflect intensified communication patterns between the different groups (i.e. politician, media and citizen). Taking a look at the scores per group, they are high for media and political agents and low for citizens, meaning that, predominantly, media and political agents are inter-connected. These high out-group tendencies of political and media agents relate to a study by Ausserhofer and Maireder (2013) on political tweeting in Austria that shows more dense and interlinked networks between established actors (i.e. politicians, journalists and experts).

To conclude, the measure of 'reciprocity' allows us to define whether communication works in both directions and how this relates to the positions the agents hold as political, media or citizen agents. The measure takes into account to what extent political, media or citizen agents reply or mention users that replied or mentioned them first. Again, this measure is calculated on group level, to understand whether political, media or citizen agents differ in reciprocity.

We specifically point to the first two columns in Table 4, which show that for citizens, reciprocity towards political and media agents is consistently higher than the other way around (i.e. columns 3 and 4). When citizens receive mentions and replies from these agents, they are more likely to respond than when political or media agents receive mentions or replies from citizens. This pattern is found for each of the four periods, although, in the week after the elections, citizens are less reciprocal towards politicians. In general, we can state that variations in symbolic capital (i.e. legitimation), which we define as the number of mentions and replies one receives, are related to the positions the agents hold as politician, media or citizen agent. In addition, the variance in conversation practices on Twitter is significantly related to the different user types. Below, we wrap up the main findings and elaborate upon future theoretical endeavours and the limitations of the study. 


\section{Discussion}

Conversations on Twitter are understood within a broad conceptual framework, or field. The structure of these conversations allows us to understand how Twitter is related to the political and the media field. In this respect, this article adds perspectives to the theoretical understanding of the role of social media in the public debate. We defined different aspects of autonomy related to the presence of the different agent types, their positions in the conversation networks and the conversation practices between each of the groups. Via our network analyses and statistical comparison between the different agent types, we provide new methods and measures to better understand these emerging practices.

At the beginning of this article, we discussed the affordances of Twitter and how they can alter relations between (1) the media and their audiences, and (2) politicians and their electorate. In essence, we understand the public debate as a combination of and overlap between three fields. Within this framework, we understand the relatedness between the fields and to what extent these emerging spheres (e.g. Twitter) resemble the existing ones (the political and the media field). In turn, we pose the following questions: How autonomous should Twitter be? How can autonomy enhance democracy or even reflect potential shifts in power? The relatedness between the fields allows us to define different arenas and different perspectives for change, and hence, different answers for these questions.

In the following, we define specific limitations of this study in relation to avenues for future work, whereby we distinguish between methodological and theoretical issues. First, we point to the time-bound character and social specificity of our analyses. Fields (and their logics and occupants) evolve over time and other countries, different contexts (e.g. outside elections) or social media platforms potentially generate other levels of autonomy and dependency. Second, concerning data collection and analysis, we acknowledge that the hashtag approach influences the choice of messages we collected and the measures we calculated. Results could be different when we depart from a collection of users to con- struct conversation networks. Concerning follow-up research, we point to content analyses to better understand the differences in conversation practices. In addition, in-depth interviews could reveal how the different agent types perceive these structures and whether there are contradictory findings between our measures and their perceptions. 
The notion of capital, which received only peripheral attention in this article but which is central in the struggle over positions in the field, also needs further elaboration. Aside mentions and replies, other field-specific attributes of the agents can provide additional explanatory power for the positions the agents hold in the field (e.g. general user activity or creativity/diversity in content). In addition, understanding the practices of agents within the field in relation to their positions in other fields can benefit from elaboration upon the notions of illusio (i.e. the belief that the game or struggle for capital is worth playing) and doxa (i.e. tacit presuppositions that organize action within the field) (Bourdieu, 1990). We can wonder to what extent agents vary in their understanding of the game and/or the fact that the game is worth playing. Perhaps for citizens, it makes more sense to engage in the game as they are dominated, whereas political and media agents already hold dominant positions in the conversation network. Related to this, we touch upon Couldry's (2003) notion of media metacapital or the power to confer legitimacy across fields. This concept allows us to understand how media attention (of people and/or issues) translates into power across fields, that is, to the general society. Such a perspective would benefit from the understanding of the interdependencies between mainstream and social media, in a political as well as other contexts. The field-based approach allows a systemic and multidimensional understanding of these platforms through the focus on specific agents and related practices, as these agents and their respective fields collide in contemporary multi-media landscape.

\section{REFERENCES}

Ausserhofer J and Maireder A (2013) National politics on Twitter. Information, Communication \& Society 16(3): 291-314.

Benkler Y (2006) The wealth of networks. How social production transforms markets and freedom. New Haven, CT: Yale University Press.

Benson R and Neveu E (2005) Bourdieu and the journalistic field. Cambridge, MA: Polity Press.

Borgatti SP (2007) Typology of ties. Keynote speech presented at the international Sunbelt conference. St. Petersburg, Florida.

Borgatti SP, Everett MG and Freeman LC (2002) Ucinet for Windows: Software for Social Network Analysis. Harvard, MA: Analytic Technologies.

Benson R (2009) Shaping the public sphere: Habermas and beyond. The American Sociologist 40(3): 175-197. 
Bourdieu P (1984) Distinction: A social critique of the judgement of taste (R Nice, Trans.). Cambridge, MA: Harvard University Press.

Bourdieu P (1986) The forms of capital. In: Richardson J (ed) Handbook of theory and research for the sociology of education. New York, NY: Greenwood, pp. 241-258.

Bourdieu P (1988) Homo Academicus (P Collier, Trans.). Cambridge, MA: Polity Press.

Bourdieu P (1990) The logic of practice (R Nice, Trans.). Cambridge, MA: Polity Press.

Bourdieu P (1991) In: Thompson J (ed) Language and symbolic power (G Raymond and M Adamson, Trans.). Cambridge, MA: Harvard University Press.

Bourdieu P (1993) The field of cultural production. Cambridge, MA: Polity Press.

Bruns A (2005) Gatewatching: Collaborative Online News Production. New York, NY: Peter Lang.

Bruns A (2012) How long is a tweet? Mapping dynamic conversation networks on Twitter using Gawk and Gephi. Information, Communication \& Society 15(9): 1323-1351.

Bruns A and Burgess J (2011) \#Ausvotes: How Twitter covered the 2010 Australian federal election. Communication, Politics \& Culture 4(2): 37-56.

Bruns A and Highfield T (2013) Political networks on Twitter. Tweeting the Queensland state election. Information, Communication \& Society 16(5): 667-691.

Castells M (2009) Communication Power. Oxford: Oxford University Press.

Coleman S (2003) A tale of two hourses: The house of commons, the Big Brother house and the people at home. Parliamentary Affairs 56(4): 733-758.

Couldry N (2003) Meta-Capital: Extending the range of Bourdieu's field theory. Theory and Society 32(5/6): 653-677.

De Bens E and Raeymaeckers K (2010) De pers in België. Leuven: Lannoo Campus.

de Nooy W (2003) Fields and networks: Correspondence analysis and social network analysis in the framework of field theory. Poetics 31(5-6): 305-327.

Epping L, De Smedt J, Walgrave S and Hooghe M (2013) Gemeenteraadsverkiezingen 2012: Er werd vooral over de N-VA gesproken. Media-aandacht voor politici in de gemeenteraadsverkiezingsprogramma's van 2012 op de VRT: Het Steunpunt Media.

Fairclough N (1994) Conversationalization of public discourse and the authority of the consumer. In: Keat R, Whiteley $\mathrm{N}$ and Abercrombie $\mathrm{N}$ (eds) The authority of the consumer. London: Routledge, pp. 252-268.

Fenton N (2012) The internet and social networking. In: Curran J, Fenton N and Freedman D (eds), Misunderstanding the internet. New York: Routledge, pp. 123-148. 
Fenton N and Barassi V (2011) Alternative media and Social Networking Sites: The politics of individuation and political participation. The Communication Review 14(3): 179196.

Friedland LA, Hove T and Rojas H (2006) The networked public sphere. Javnost-The Public 13(4): 5-26.

Giddens A (1991) Modernity and self-identity: Self and society in the late modern age. Cambridge: Polity Press.

Gillmor D (2004) We, The media. Cambridge, MA: O-Reilly Media Inc.

Graham T, Broersma M, Hazelhoff K and van 't Haar G (2013) Between broadcasting political messages and interacting with voters. Information, Communication \& Society. doi: 10.1080/1369118X.2013.785581

Hallin DC and Mancini P (2004) Comparing media systems: Three models of media and politics. Cambridge, MA: Cambridge University Press.

Hanneman RA and Riddle M (2011) Concepts and measures for basic network analysis. In: Scott J and Carrington PJ (eds), The SAGE handbook of Social Network Analysis. London: Sage Publications Ltd, pp. 340-369.

Heinrich A (2011) Network Journalism. Journalism practice in interactive spheres. New York, NY: Routledge.

Hjarvard S (2013) The Mediatization of culture and society. London: Routledge.

Honeycutt C and Herring SC (2009) Beyond Microblogging: Conversation and collaboration via Twitter. Paper presented at the Forty-Second Hawaii International Conference on System Sciences, Los Alamitos, CA.

Howard PN (2006) New media campaigns ant the managed citizen. New York, NY: Cambridge University Press.

iMinds-iLab.o (2012) Digimeter Report 5. Adoption and usage of Media \& ICT in Flanders. Ghent: iMinds-iLab.o.

Jenkins H (2006) Convergence culture: Where old and new media collide. New York, NY: New York University Press.

Kauppi N (2003) Bourdieu's political sociology and the politics of European integration. Theory and Society 32(5/6): 775-789.

Krackhardt D and Stern R (1988) Informal networks and organizational crises: An experimental simulation. Social Psychology Quarterly 15(2): 123-140.

Larsson A and Moe H (2012) Studying political microblogging: Twitter users in the 2010 Swedish election campaign. New Media \& Society 14(5): 729-747. 
Lilleker D and Vedel T (2013) The internet in campaigns and elections. In: Dutton WH (ed), The Oxford handbook of internet studies. Oxford: Oxford University Press, pp. 401420.

Maton K (2005) A question of autonomy: Bourdieu's field approach and higher education policy. Journal of Education Policy 20(6): 687-704.

Meraz S and Papacharissi Z (2013) Networked gatekeeping and networked framing on \#egypt. The International Journal of Press/Politics 18(2): 138-166.

Murthy D (2013) Twitter. Cambridge: Polity Press.

Papacharissi Z and Easton E (2013) In the habitus of the new. Structure, agency and the social media habitus. In: Hartley J, Burgess J and Bruns A (eds), A companion to new media dynamics. West Sussex, UK: Blackwell Publishing Ltd, pp. 171-184.

Prior M (2006) Post-broadcast democracy: How media choice increases inequality in political involvement and polarizes elections. Cambridge: Cambridge University Press.

Rieder B (2012) The refraction chamber: Twitter as sphere and network. First Monday 17(11): 170-186.

Shirky C (2008) Here comes everybody: The power of organizing without organizations. New York: Penguin Press.

Sjöberg U and Rydin I (2013) Transmedia storytelling and a young audience. In: Olsson T (ed), Producing the internet. Critical perspectives of social media. Göteborg, Sweden: Nordicom, pp. 103-120.

Song FW (2010) Theorizing Web 2.0. Information, Communication \& Society 13(2): 249-275. Svensson J (2011) Power and Participation in Digital Late Modernity - Towards a Network Logic. In: Tambouris E, Macintosh A \& and Bruijn H (eds). Electronic Participation: Third IFIP WG 8.5 International Conference, ePart 2011, Delft, The Netherlands, August/September 2011 Proceedings. LNCS 6847. IFIP International Federation for Information Processing. Berlin: Springer, pp. 109-120.

Swartz D (1997) Culture and power. The sociology of Pierre Bourdieu. Chicago: The University of Chicago Press.

Van Aelst P (2008) De lokale verkiezingscampagne: tussen huisbezoek en televisiestudio. In: Buelens J, Rihoux B and Deschouwer K (eds), Tussen Kiezer en hoofdkwartier. Brussel: VUBPRESS, pp. 95-110.

Van Dijck J and Poell T (2013) Understanding Social Media Logic. Media and Communication 1(1): $2-14$ 
Vergeer M, Hermans L and Sams S (2011) Online social networks and micro-blogging in political campaigning: The exploration of a new campaign tool and a new campaign style. Party Politics. doi: 10.1177/1354068811407580 
Table 1 (Relative) count of the different agents per period

\begin{tabular}{lcccc}
\hline & \multicolumn{3}{c}{ Agents } \\
& $\begin{array}{c}\text { Politicians } \\
(N=425)\end{array}$ & $\begin{array}{c}\text { Media } \\
(N=271)\end{array}$ & $\begin{array}{c}\text { Citizens } \\
(N=1393)\end{array}$ & Total \\
\hline Pre-election & 295 & 119 & 383 & $\mathbf{7 9 7}$ \\
$(01-09-12$ to 07-10-12) & $(37 \%)$ & $(15 \%)$ & $(48 \%)$ & $(100 \%)$ \\
Prior week & 143 & 83 & 234 & $\mathbf{4 6 0}$ \\
$(08-10-12$ to $13-10-12)$ & $(31 \%)$ & $(18 \%)$ & $(51 \%)$ & $(100 \%)$ \\
Election day & 90 & 119 & 585 & $\mathbf{7 9 4}$ \\
$(14-10-12)$ & $(11 \%)$ & $(15 \%)$ & $(74 \%)$ & $(100 \%)$ \\
Post-election & 129 & 94 & 530 & $\mathbf{7 5 3}$ \\
$(15-10-12$ to $21-10-12)$ & $(17 \%)$ & $(13 \%)$ & $(70 \%)$ & $(100 \%)$ \\
\hline
\end{tabular}


Table 2 In-degree centrality by period ${ }^{+}$

\begin{tabular}{ccccc}
\hline & Political agents & Media agents & Citizen agents & $F^{* * *}$ \\
\hline Period 1 & $M=2.60(S D=$ & $M=3.24(S D=7.98)$ & $M=.80(S D=$ & $18.63(2$, \\
& $5.61)$ & & $1.49)$ & $797)$ \\
Period 2 & $M=2.20(S D=$ & $M=2.57(S D=4.44)$ & $M=.59(S D=$ & $19.31(2$, \\
& $4.04)$ & & $1.08)$ & $457)$ \\
Period 3 & $M=3.36(S D=$ & $M=2.95(S D=6.23)$ & $M=.85(S D=$ & $37.55(2$, \\
& $5.39)$ & & $1.49)$ & $791)$ \\
Period 4 & $M=4.16(S D=$ & $M=3.57(S D=8.57)$ & $M=.57(S D=$ & $27.37(2$, \\
& $11.41)$ & & $1.28)$ & $750)$
\end{tabular}

+ From here on: P1: Pre-election (01-09-12 to 07-10-12), P2: Prior week (08-10-12 to 13-1012),

P3: Election day (14-10-12), P4: Post-election (15-10-12 to 21-10-12)

$* * * \mathrm{p}<.001$ 
Table 3 General and group level E-I index ${ }^{+}$by period

\begin{tabular}{lcc|ccc}
\hline & Observed (Expected) & standard error & $\begin{array}{c}\text { Political } \\
\text { agents }\end{array}$ & Media agents & Citizens \\
\hline Period 1 & $0.278(0.220)$ & $S D=0.037$ & 0.089 & 0.679 & 0.280 \\
Period 2 & $0.325(0.227)$ & $S D=0.047$ & 0.103 & 0.407 & 0.254 \\
Period 3 & $0.140 *(-0.155)$ & $S D=0.056$ & 0.604 & 0.596 & -0.157 \\
Period 4 & $0.430 *(-0.079)$ & $S D=0.086$ & 0.661 & 0.617 & 0.235 \\
\hline
\end{tabular}

+ The E-I index is calculated as follows: [the number of ties external to the group - the number of ties internal to the group]/[the total number of ties]. The results range from - 1 [all ties internal] to +1 [all ties external]

$* \mathrm{p}<.05$ 
Table 4 Reciprocity ${ }^{*}$ by period

\begin{tabular}{lcccccc}
\hline & $M \rightarrow C$ & $P \rightarrow C$ & $P \rightarrow M$ & $C \rightarrow P$ & $C \rightarrow M$ & $M \rightarrow P$ \\
\hline Period 1 & $12 \%$ & $12.87 \%$ & $1.11 \%$ & $5.31 \%$ & $1.79 \%$ & $1.12 \%$ \\
Period 2 & $20 \%$ & $12.9 \%$ & $2.22 \%$ & $3.28 \%$ & $4.26 \%$ & $3.23 \%$ \\
Period 3 & $14.29 \%$ & $11.54 \%$ & $14.29 \%$ & $1.84 \%$ & $2.57 \%$ & $1.96 \%$ \\
Period 4 & $22.22 \%$ & $5.45 \%$ & $3.23 \%$ & $0.87 \%$ & $0.97 \%$ & $2.86 \%$
\end{tabular}

* The table gives the percentages for each of the ties going from actor A to actor B that are reciprocated. 